\title{
Land-Use/Land-Cover Dynamics in Calabar Metropolis Using a Combined Approach of Remote Sensing and GIS
}

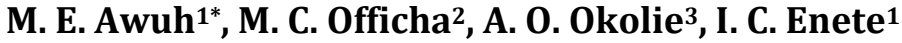 \\ ${ }^{1}$ Department of Geography and Meteorology, NAU, Awka, Nigeria \\ ${ }^{2}$ Department of Architecture, NAU, Awka, Nigeria \\ ${ }^{3}$ Department of Architecture, Chukwuemeka Odumegwu Ojukwu University, Uli, Nigeria \\ Email: *awuhekolok@yahoo.co.uk
}

How to cite this paper: Awuh, M.E., Officha, M.C., Okolie, A.O. and Enete, I.C. (2018) Land-Use/Land-Cover Dynamics in Calabar Metropolis Using a Combined Approach of Remote Sensing and GIS. Journal of Geographic Information System, 10, 398-414.

https://doi.org/10.4236/jgis.2018.104021

Received: June 19, 2018

Accepted: August 14, 2018

Published: August 17, 2018

Copyright (c) 2018 by authors and Scientific Research Publishing Inc. This work is licensed under the Creative Commons Attribution International License (CC BY 4.0).

http://creativecommons.org/licenses/by/4.0/

\begin{abstract}
This paper assessed the dynamics in the land use/land cover (LULC) within patterns of the land use/land cover (LULC) in Calabar metropolis. The thermal imageries for 2002, 2006, 2008, 2010, 2012, 2014 and 2016 were obtained and processed using remote sensing and Arc GIS software package in order to determine the changes that have occurred in the LULC in study area. The result of the LULC thematic maps overall accuracies was computed above 80 percent, which indicates an almost perfect agreement. The findings of this study reveal that, LULC classes by the year 2016 have assumed different dimensions of change from the sizes of their previous sizes in comparison to their current sizes. Land-use pattern changes in the study area were characterized by an increase in the built up class, waterbody (though with a slightly negative change from 2010 to 2012) and a predominant negative trend in dense vegetation and bare land classes; thus, indicating that the future changing trends will pose a depleting threat to the overall LULC. This study has shown that, the changing land use pattern of the area is capable affecting certain characteristics of the environment such as surface temperature. The study recommends that effort should be made by the government to increase urban vegetation around city centers and outliers by embarking on reforestation.
\end{abstract}

\section{Keywords}

Remote Sensing, GIS, Calabar, Land Use/Cover Change

\section{Introduction}

Land use/cover (LULC) is an important component to understand the changes 
in the environment triggered by the interaction between human and the environment. Population increased to major cities has resulted in urban sprawl at an unprecedented rate, which according to [1] analysis and prediction report, is projected to continue into the next era. The geometric increase in the global population has necessitated the building of services such as, settlements, to accommodate the growing population. These activities result in land conversion, such as, forest or plantations, agricultural lands and grasslands to grow impervious surfaces such as roads, sidewalks, parking lots, rooftops and bare lands [2] [3] [4]. According to numerous studies [5] [6] [7] [8], land conversion to impervious surfaces is one of the main contributors to climate change and variability in different parts of the world which potentially affects the health of urban dwellers living in localities that continue to experience LULC changes.

More also, land-use/land-cover change contributes significantly to earth-atmosphere interactions, forest fragmentation, and biodiversity loss and has become a major issues for environmental change monitoring and natural resource management [3] [4]. Therefore monitoring land cover dynamics in the urban area, in an appropriate and cost effective manner, is very important to local communities and decision makers. It enables the planning, management and conservation of natural resources and the environment.

\section{Materials and Method}

\subsection{Study Area}

Calabar Metropolis, the study area, is the capital of Cross River State, Nigeria, located at the southern part of the State. It encompasses of Calabar Municipality and Calabar South Local Government Areas and lies between latitudes $4^{\circ} 50^{\prime} \mathrm{N}$ and $5^{\circ} 10^{\prime} \mathrm{N}$ and longitudes $8^{\circ} 17^{\prime} \mathrm{E}$ and $8^{\circ} 20^{\prime} \mathrm{E}$; bounded to the north by Odukpani Local Government Area (LGA) and to the East by Akpabuyo LGA. Calabar Metropolis is sandwiched between the Great Kwa River to the East and the Calabar River to the West. The present of urban area is on the eastern bank of the Calabar River. Its growth of the southern part is hindered by the mangrove swamps. It covers an estimated land area of about $274.593 \mathrm{~km}^{2}$ (Figure 1). Calabar falls within tropical equatorial (Af) climate of high temperature, high relative humidity and abundant annual rainfall [9]. The annual rainfall is $2750 \mathrm{~mm}$ and mean annual average temperature is $26.1^{\circ} \mathrm{C}$. The study area has witnessed a tremendous increase in the population of 10,000 estimated at the pre-colonial, to 99,352 in 1993; 328,876, in 1991. The last census in 2006 put the population to 371,022 [10]. The population growth of Calabar has been followed by the expansion of its physical boundaries. This increase in the physical boundaries implies a corresponding loss of vegetation and land in the area thereby a direct impact on the micro-climate [11].

\subsection{Image and Pre-Processing}

Landsat cloud-free imagery were acquired from the NASA web site which 


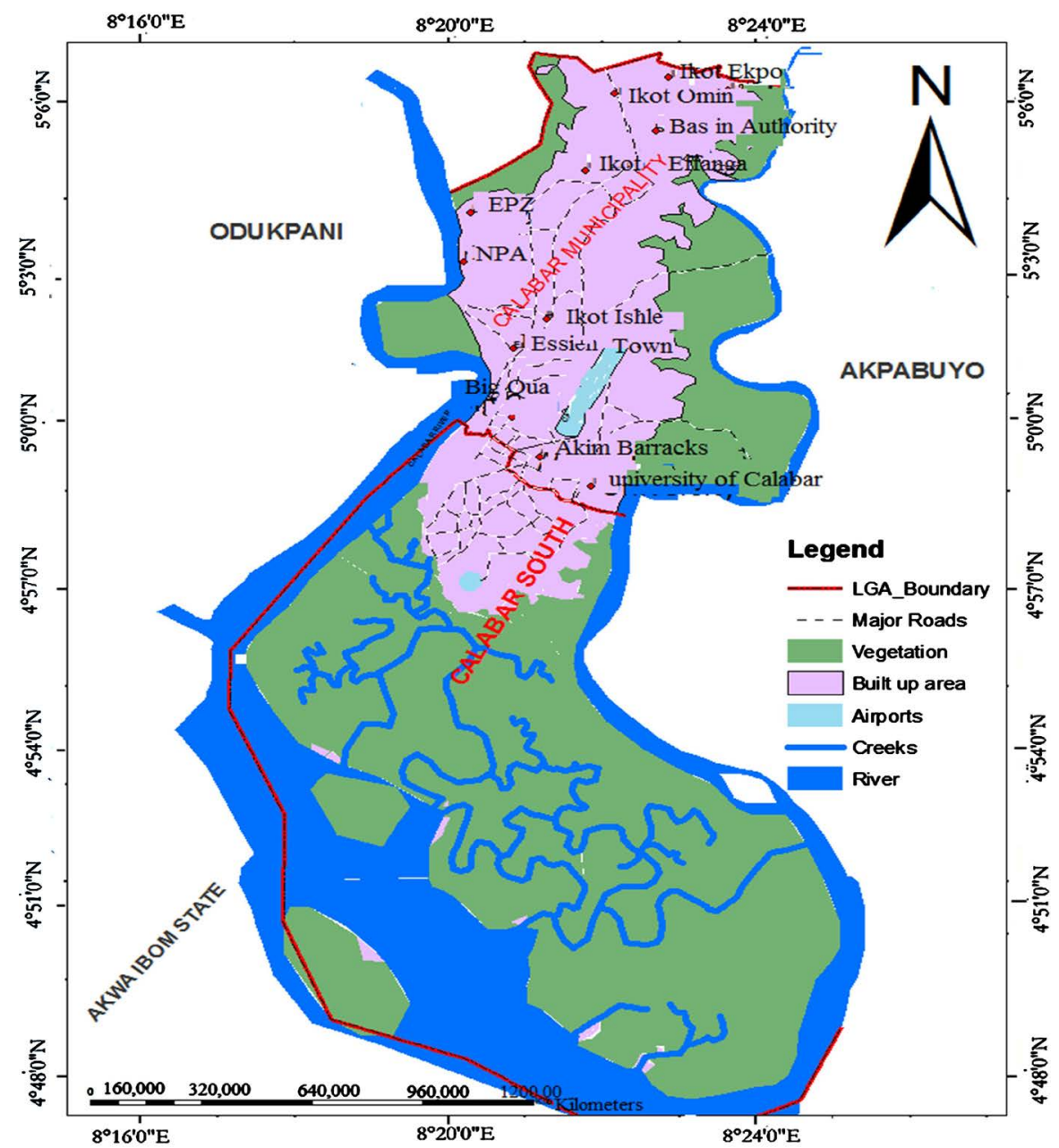

Figure 1. Map of the study area.

comprised of the Thematic Mapper (TM), Enhance Thematic Mapper plus $\left(\mathrm{ETM}^{+}\right)$image and the Operational Land Imager (OLI) to determine LULC change within Calabar Metropolis between "2002 and 2016". The imagery downloaded covered a period of 15 years at an interval of 2 years. The software employed for desktop analysis was ArcGIS. Identifying the study area was the first step of this research which was achieved with the use of an administrative map of Calabar, showing Calabar Municipality and Calabar South LGA.

\subsection{Image and Pre-Processing}

A systematically geometric, radiometric correction was performed to the image data using the Calibration Parameter File (CPF) released by the Earth Resources Observation Systems (EROS) Data Center (EDC), USGS before the satellite image were delivered. The quality of Landsat images were in 1B level. The Landsat images, including the thermal bands, were further rectified to Universal Transverse Mercator coordinate system and were re-sampled using the nearest neighbor algorithm with a pixel size of 30 by $30 \mathrm{~ms}$ for all bands and the Resultant Root Mean Square Error (RMSE) less than 0.5 pixels. A supervised classification 
was performed by creating a training sample and based on spectral signature curves; various land use types and cover classes were identified. Five land use/cover classes where identified (Table 1).

The land use was calculated using the LULC profile generation by the SVM algorithm. The urban size, development area and water proportion were extracted directly from the classification images. Here the urban size and development area of Calabar South and Calabar Municipality can be easily calculated from the sum of corresponding land-use/land-cover pixels in the classification images, while the water proportion (the ratio of water area against the total of urban area, including both land and water areas), was computed using the following equation:

$$
P=S_{\text {water }} /\left(S_{\text {water }}+S_{\text {urban }}\right)
$$

where $P$ is the water proportion, $S_{\text {water }}$ is the pixel area of water; $S_{\text {urban }}$ is the pixel area of urban-used land.

\subsection{Change Detection}

Cross tabulation was employed to determine quantities of conversions from a particular land cover to another land cover category at a later date [12]. The change matrices based on post classification comparison were obtained. Change that occurred over the study period 2002-2016 (15 years) was analyzed. The extent of the land use and land covers change in the study period was also calculated, the results were presented in maps, charts and tables.

\subsection{Land Use Land Cover (LULC) Accuracy Assessment}

Accuracy assessment tasks were performed on the 2002, 2006, 2008, 2010, 2012, 2014 and 2016 images using Kappa statistics. The Kappa statistic is generally accepted as a measure of classification accuracy for both the model as well as user of the model of classification [13]. These tasks consisted of an overall classification accuracy, Kappa statistics, and error matrix reports Kappa values are characterized as $<0$ as indicative of no agreements and $0-0.2$ as slight, $0.2-0.41$ as fair, $0.41-1160.60$ as moderate, $0.60-0.80$ as substantial and $0.81-1.0$ as almost perfect agreement [13]. The classification accuracy report calculates the statistics of percentages of accuracy relative to error matrix results. The error matrix report simply compares the historical (reference) values to the assigned class

Table 1. Land use/cover of calabar south and calabar metropolis.

\begin{tabular}{cc}
\hline No. & Class Name \\
\hline 1 & Waterbody \\
2 & Sparse Vegetation \\
3 & Dense Vegetation \\
4 & Built-Up \\
5 & Barelands \\
\hline
\end{tabular}


values. Kappa statistics measure the ability to provide information about a single matrix as well as to compare matrices [14]. The results of historical reference image obtained from the NASA website revealed that the overall classification accuracy of the images produced almost perfect Kappa statistics of 99.60 percent, 99.1 percent, 94.8 percent, 99.9 percent, and 99.6 percent for the2002, 2006, 2008, 2010, 2012, 2014 and the 2016 images, respectively. This is an indication of an almost perfect agreement.

\section{Result Presentation and Discussion}

\subsection{Satellite Images and LULC Classes Analyses}

Details of the LULC characteristics of Calabar South LGA/Calabar Municipality were identified using Landsat $7 \mathrm{ETM}^{+}$for 2002, 2006, 2008, 2010, 2012, 2015 images respectively. OLI image was used to determine the LULC characteristics for 2016. The change matrices based on post classification comparison were obtained and are shown in Tables 2-7 and Figures 2-9. The size and area of the land cover changes for the years under study were calculated and presented in hectares (ha). The result showed that there have been an increasing rate of Landover changes from the period of 2002 to 2016.

\subsection{Analysis of LULC Class Image for 2002}

Figure 2 presents the results of the LULC class image for 2002. The results of the analysis of the 2002 satellite derived image shows that a great variation exists on the area coverage percent of the different LULC identified in the study area. The results of the 2002 classified images reveals that dense vegetation and sparse vegetation classes dominated the landscape, with 19,861.42 and 3996.47 hectare (ha), representing 61 percent and 12.27 percent of the land area. This was followed by waterbody, covering 3750.37 ha (11.52\%), built-up class, covered an area of 2865.19 ha which implies, 8.80 percent of the total area. The LULC class of the lowest percent coverage in 2002 was bareland, covering a total area of 2084.76 ha, implying 6.4 percent of the total area (Figure 3 and Table 2).

\subsection{Analysis of LULC Class Image for 2006}

The result of the land use class image of 2006 is displayed in Figure 4. The result

Table 2. Area (ha)/Percentage of LULC for 2002.

\begin{tabular}{cc}
\hline Class Name & $\%$ \\
\hline Waterbody & 11.52 \\
Sparse Vegetation & 12.27 \\
Dense Vegetation & 61 \\
Built-Up & 8.8 \\
Barelands & 6.4 \\
\hline
\end{tabular}




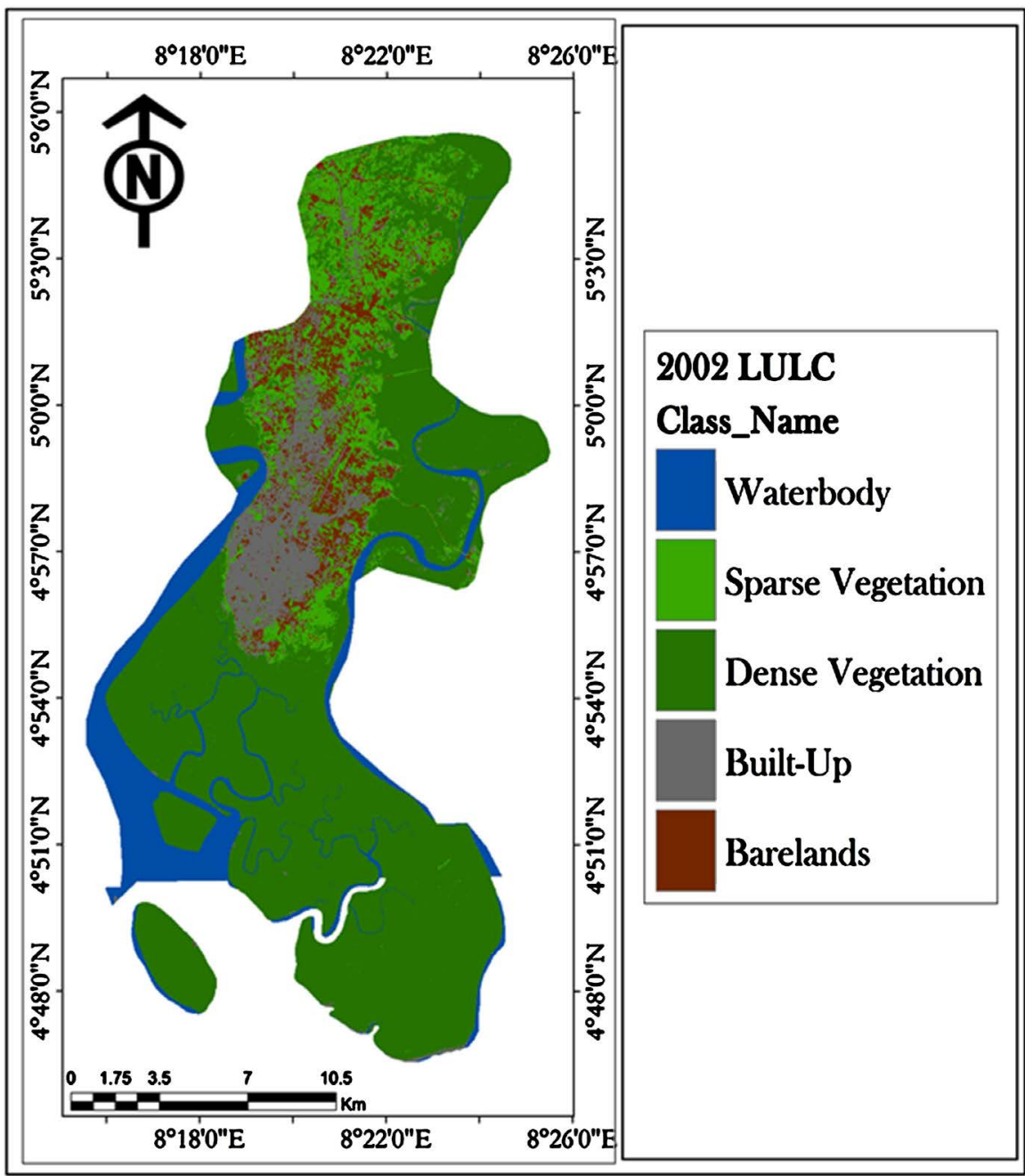

Figure 2. LULC Map of 2002 Landsat $7 \mathrm{ETM}^{+}$image.

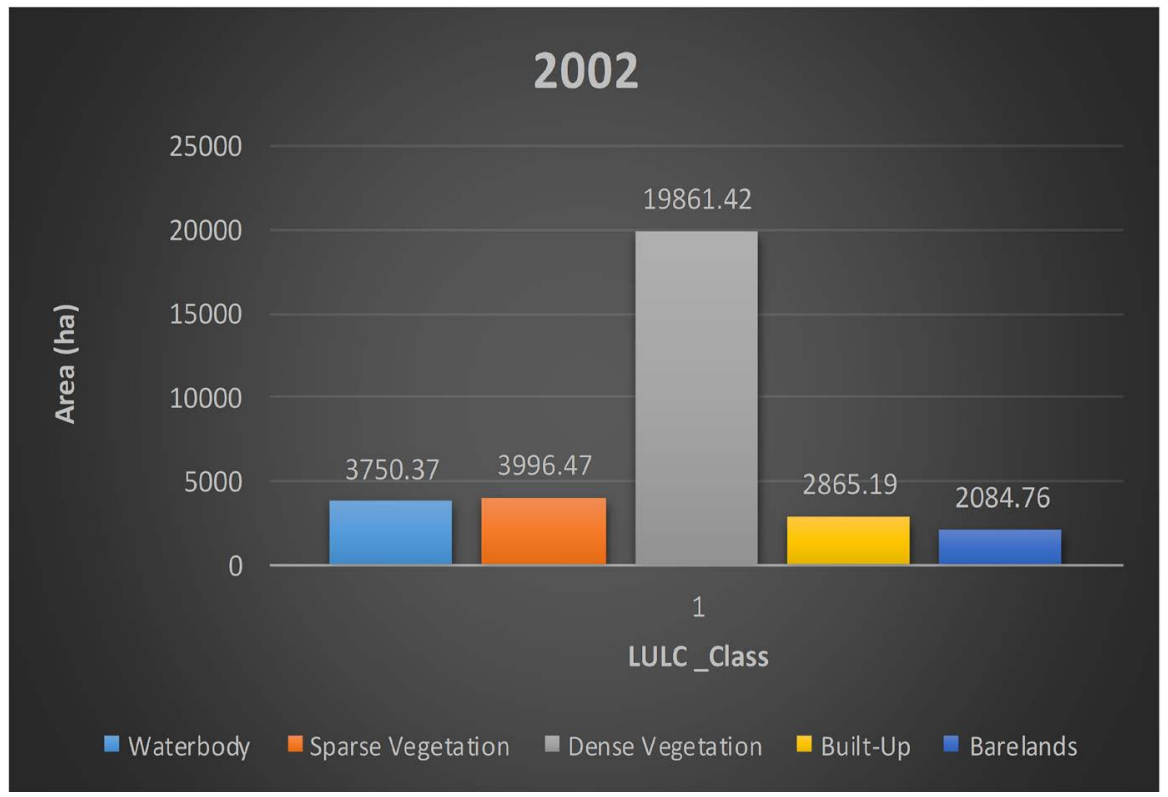

Figure 3. Area coverage of the different LULC in ha for 2002. 
revealed that, in 2006, built up class occupied a total surface area of 3577.14 ha, 1762.34 ha was occupied by barelands, dense vegetation and waterbody occupied $16,929.7$ ha and 3544.67 respectively (Table 3 ). The result further showed a considerable increase in the built up cover by 711.95 ha, representing 10.9 percent of the total LULC classes of the area (Table 3 and Figure 5).

Also, a decrease of 2931.71 ha was observed in the area covered by dense vegetation in 2016 compared to the 2002 (61\% to 52\%), the area coverage for barelands also decreased by 322.41 ha in 2006 compared to 2002. The 322.41 ha of barelands loss from 2002 to 2006 was converted to build up area, which accounts for the increase in the built up cover (Figure 5).

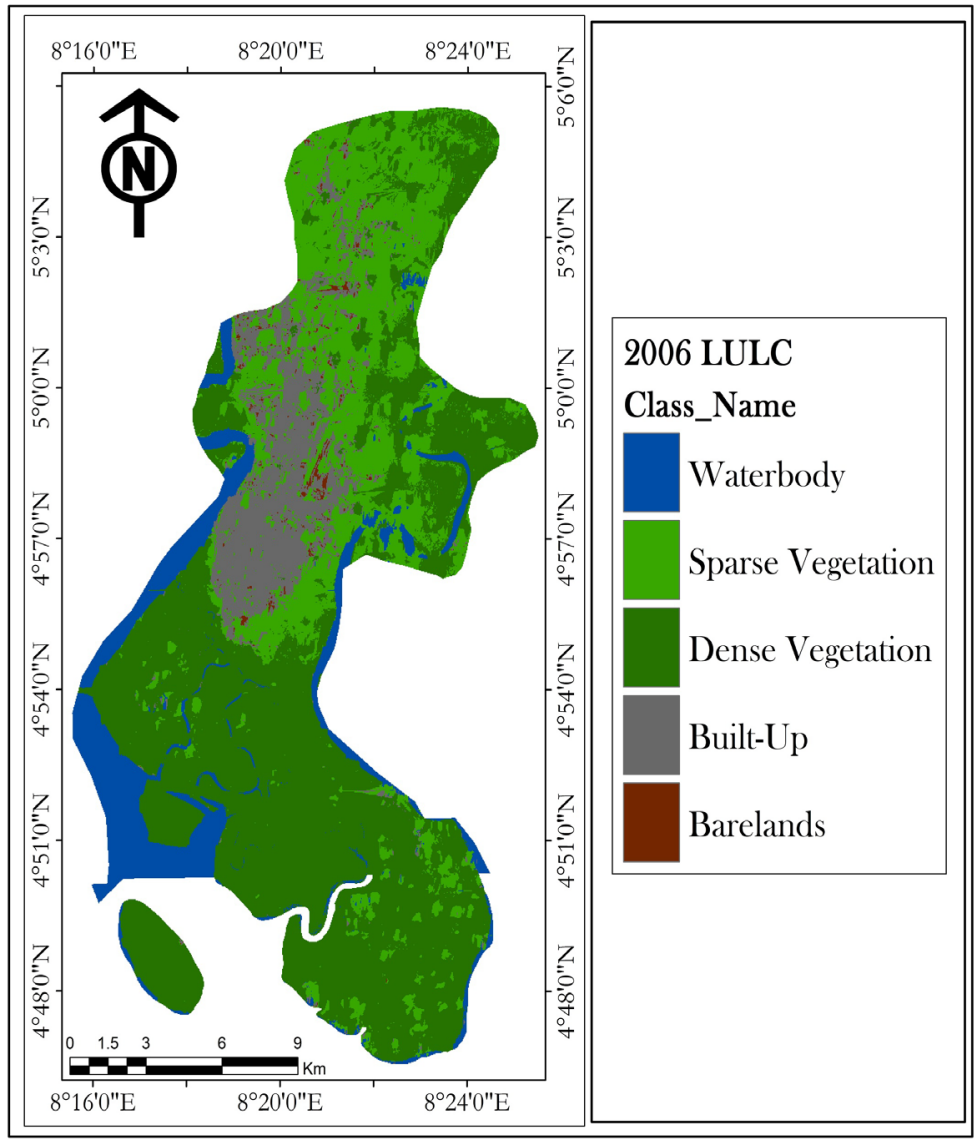

Figure 4. LULC Map of 2006 Landsat $7 \mathrm{ETM}^{+}$image.

Table 3. Area (ha)/Percentage of LULC for 2006.

\begin{tabular}{cc}
\hline & 2006 \\
\hline Class Name & Area (ha) \\
\hline Waterbody & 3544.67 \\
Sparse Vegetation & 6744.36 \\
Dense Vegetation & 16929.7 \\
Built-Up & 3577.14 \\
Barelands & 1762.34 \\
& 32558.21 \\
\hline
\end{tabular}


Figure 5 displays the percentage of LULC classes in 2006 with dense vegetation having the highest percent cover (52\%). This was followed by sparse vegetation with 20.7 percent, built up with 10.99 percent cover. The LULC types with the lowest percent cover in 2006 were water and bare land with 10.89 percent and 5.1 percent respectively with barelands having the least percent cover.

\subsection{Analysis of LULC Class Image for 2008}

The results of the 2008 land-use class image (Figure 6) revealed a considerable

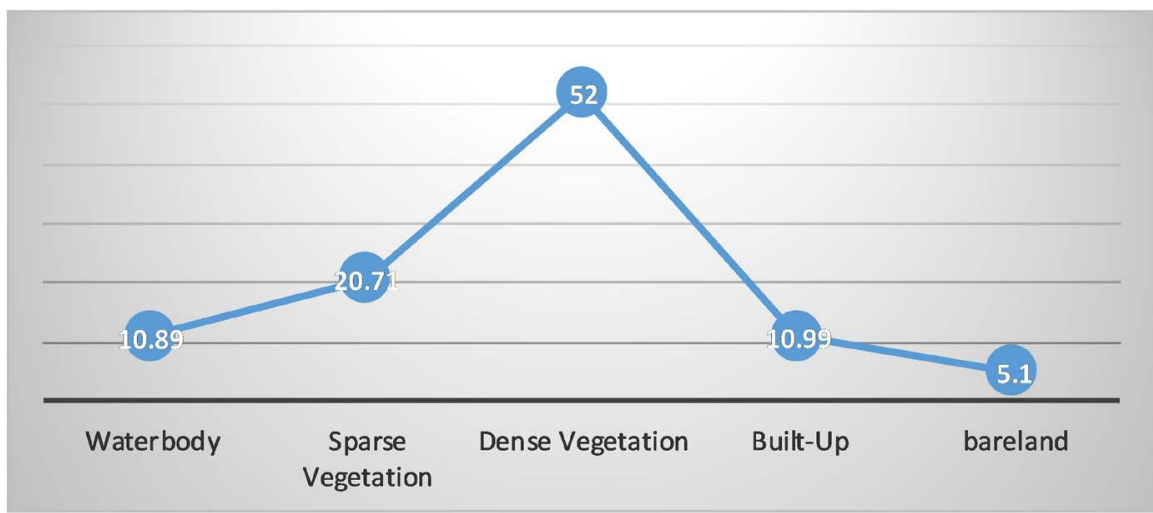

Figure 5. Line graph showing percentage of LULC for 2006.

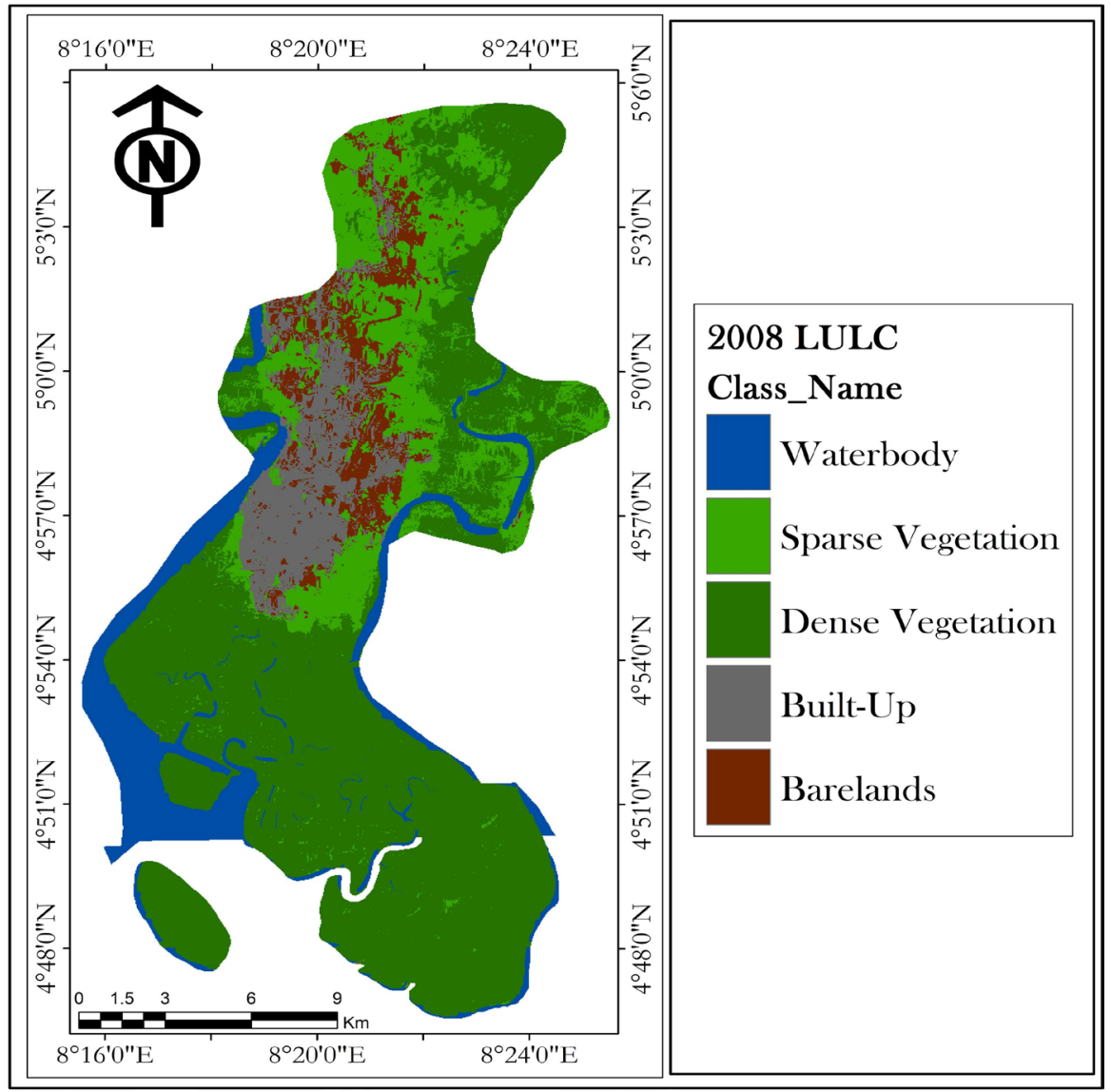

Figure 6. LULC Map of 2008 Landsat $7 \mathrm{ETM}^{+}$image. 
change in the LULC classes compared to the previous years under study (Figure 7, Figure 8).

As seen in Figure 7 and Figure 8, the total area of dense vegetation cover in 2008 was $17,897.57$ ha representing 54.97 percent of the entire Metropolitan LULC. The result further reveled a decrease in the LULC cover by 1963.85 ha for dense vegetation compared to the 2002 image. This deficit in the area coverage on the dense vegetation led to the increase in certain land areas such as built-up area with $3942.37 \mathrm{ha}$, as well as sparse vegetation, with 5935.43 ha comparison to the 2002 image. The area coverage for waterbody, sparse vegetation decreases comparison to the 2006 image, measuring up to about 12.11 percent and 18.23 percent respectively (Figure 7 and Figure 8). Barelands class was identified to be 1035.01 ha, representing 3.1 percent of the area coverage (Figure 7 and Figure 8). The results of the 2008 image indicated a drastic negative trend in the barelands class coverage with a decrease of 1049.75 ha, compared to 2002 image and a decrease of 727.33 ha compared to the 2006 image. Furthermore, waterbody in that year was 3747.83 ha representing 11.51 percent of the total area. There was an increase in the area coverage of waterbody within this year with a gain of 203.16 ha from 2006 to 2008.

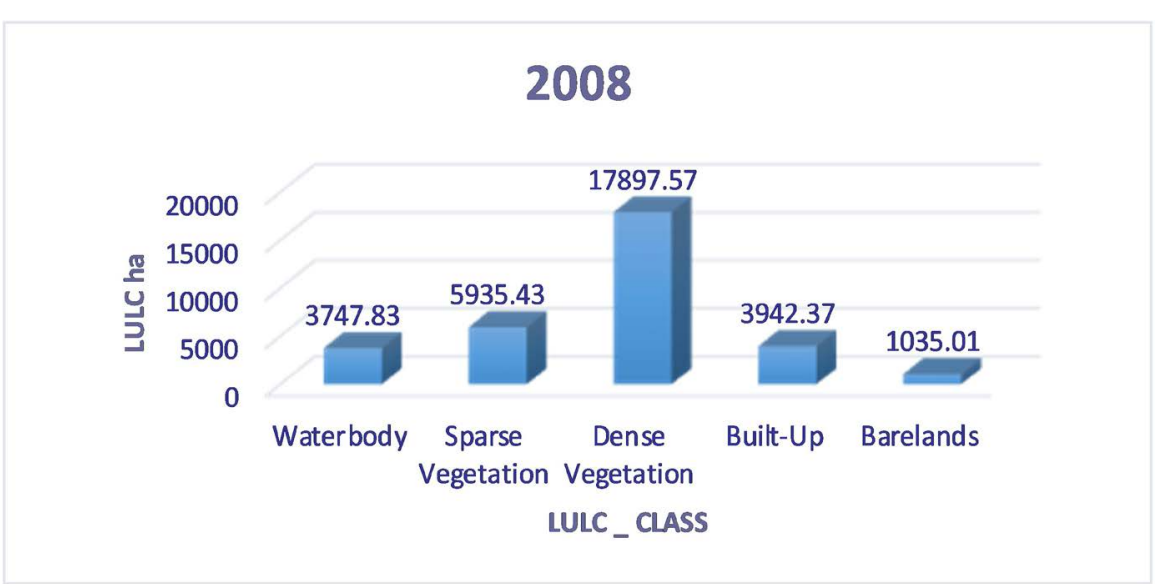

Figure 7. Land use land cover classes area (ha) for 2008.

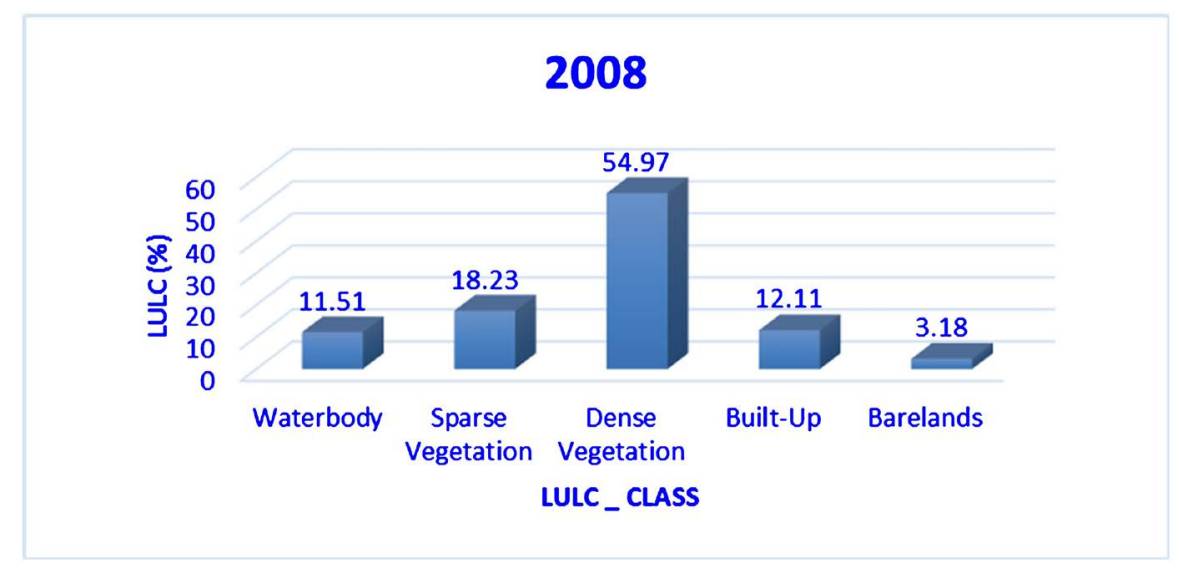

Figure 8. Land use land cover classes area (ha) of 2008. 
Furthermore, from Figure 7 and Figure 8, we observed that, in 2008 the land use class of the greatest cover was dense vegetation with 54.97 percent, followed by sparse vegetation. Built-up area and bare lands had the least percent/area coverage.

\subsection{Analysis of LULC Class Image for 2010}

The results of the LULC image for 2010 revealed some astonishing alteration as far as the area coverage of the corresponding land uses are concerned (Table 4).

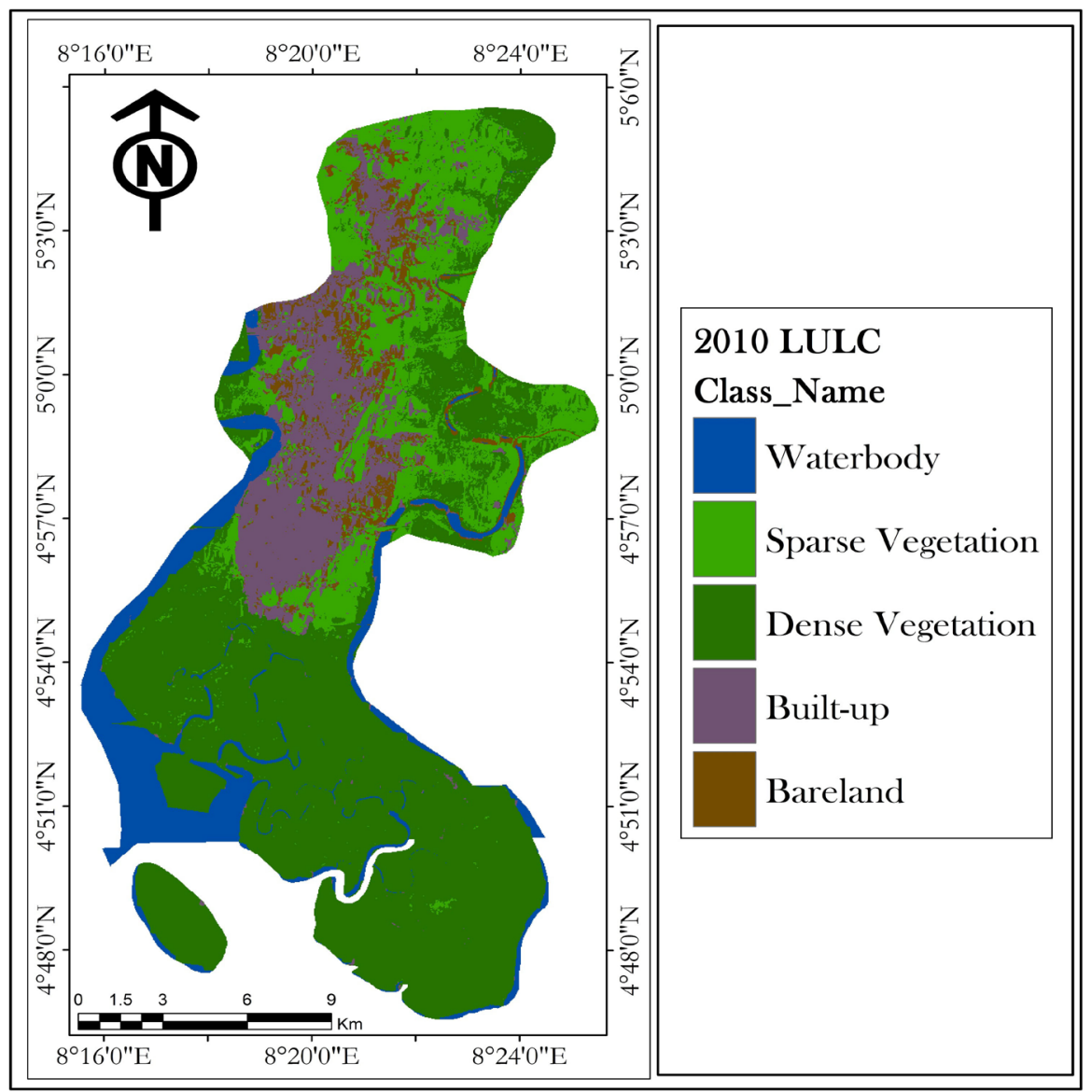

Figure 9. LULC Map of 2010 Landsat $7 \mathrm{ETM}^{+}$image.

Table 4. Land use land cover classes area (ha)/percent of 2010.

\begin{tabular}{ccc}
\hline & \multicolumn{2}{c}{$\mathbf{2 0 1 0}$} \\
\cline { 2 - 3 } Class Name & Area & $\%$ \\
\hline Waterbody & 3468.49 & 10.65 \\
Sparse Vegetation & 6413.92 & 19.70 \\
Dense Vegetation & 16560.98 & 50.87 \\
Built-Up & 4594.32 & 14.11 \\
Barelands & 1520.5 & 4.67 \\
& 32558.21 & \\
\hline
\end{tabular}


The results of the analysis of the 2010 LULC class image further demonstrated dense vegetation cover to be the class of the highest cover in 2010, thus, maintaining its high area coverage (Table 4) with $16,560.98$ ha, representing 50.87 percent of the total area, followed by sparse vegetation and built-up classes with 6413.92 ha and 4594.32 ha, respectively (19.70\% and 14.11\%) The results further revealed that the area covered by waterbody was 3468.49 ha representing about (10.65\%) of the area indicating an increase in the area coverage in comparison to other years.

\subsection{Analysis of LULC Classes for 2012 Image}

Figure 10 shows the results of the LULC image of 2012. The results of this study revealed that the built-up and barelands classes continued to experience increasing trends compared to the other land use classes, dense vegetation class maintain its high area of coverage with $17,760.39$ ha, representing 54.55 percent of the total area of LULC, sparse vegetation was next, covering an area of 4902.21 with 15.06 percent (Figure 11). The results further revealed a very wide margin of dense vegetation and the other LULC identified. Based on the results, the area coverage for the other land uses of 2012 fell below 5000 ha, dense vegetation cover an area of above 17,760.39 ha (Figure 11).

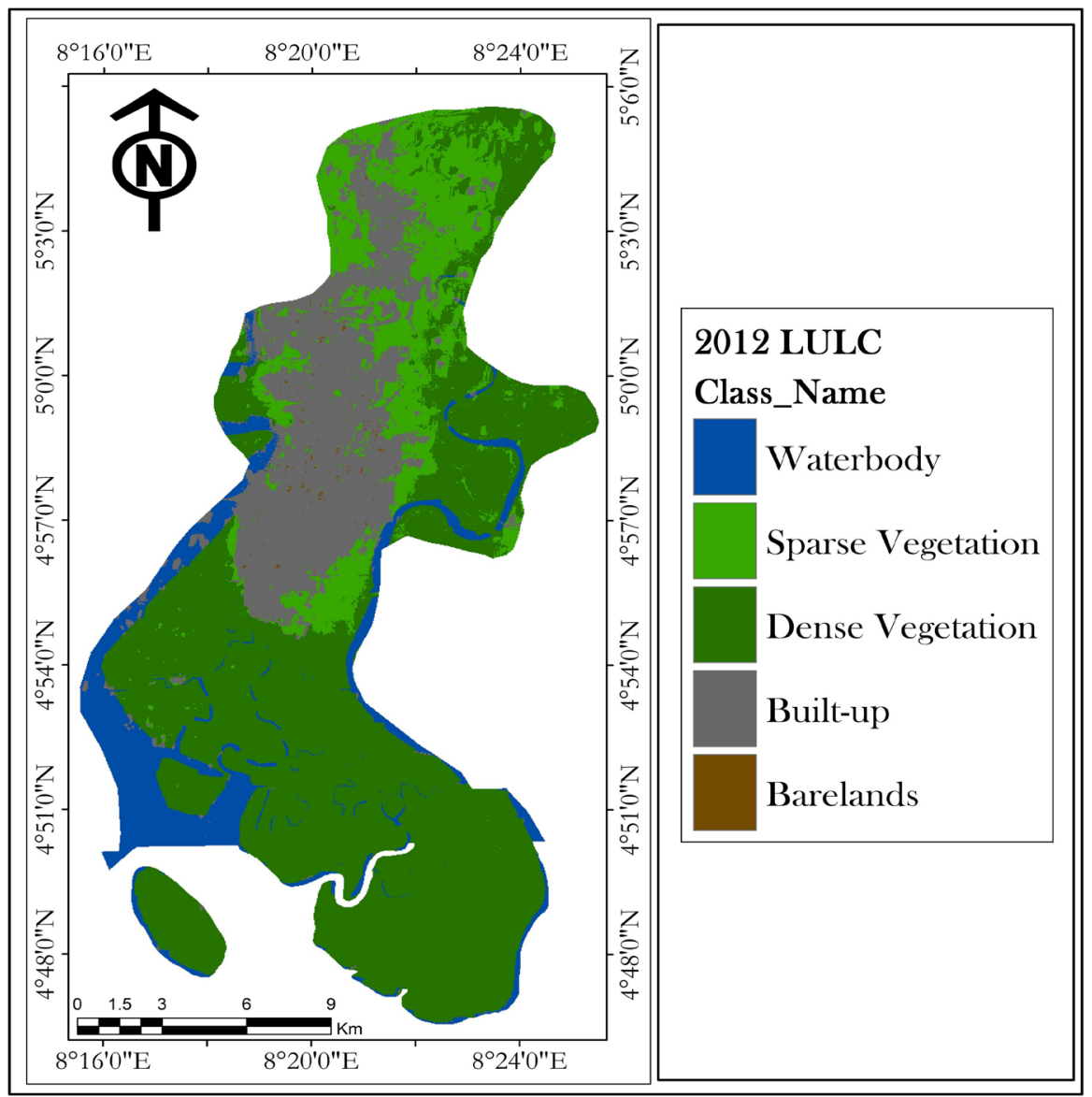

Figure 10. LULC Map of 2012 Landsat $7 \mathrm{ETM}^{+}$image. 


\subsection{Analysis of LULC Classes for 2014 Image}

The result as derived from the satellite imagery, revealed that, by 2014, the total area coverage of almost all the land use classes has change completely. Built-up area, barelands and sparse vegetation occupied the following area; 5380.89 ha, 3822.59 ha, 7373.34 respectively (Figure 12 ).

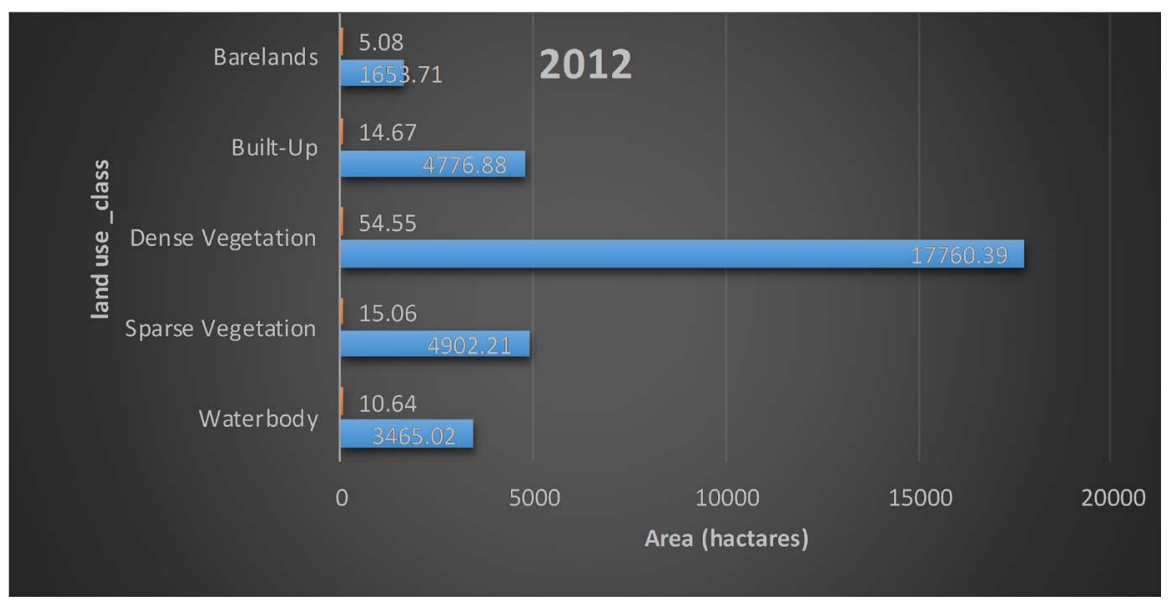

Figure 11. Land use land cover classes area (ha) for 2012.

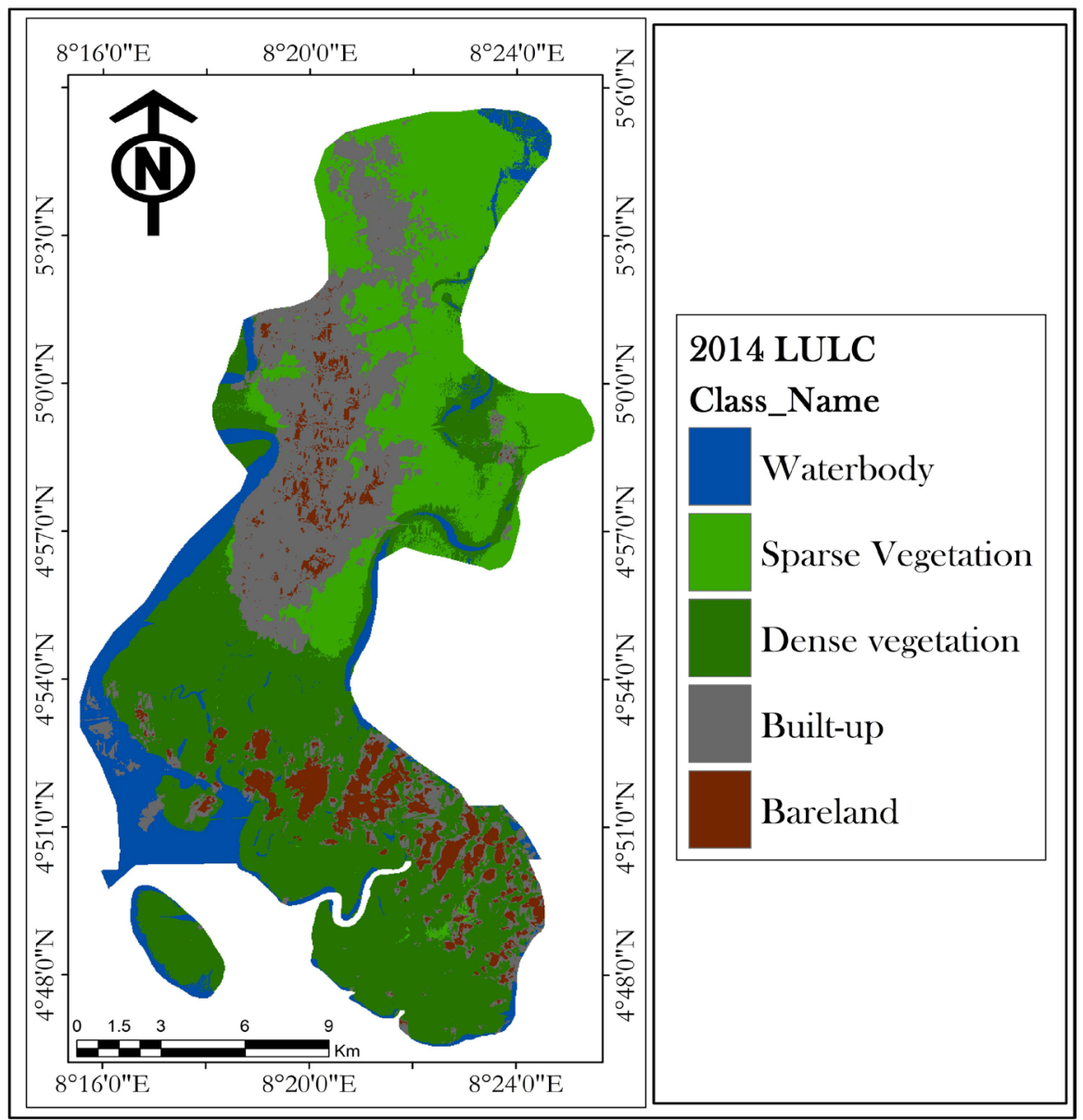

Figure 12. LULC Map of 2014 Landsat $7 \mathrm{ETM}^{+}$image. 
Figure 13 displays the area coverage for the five land use land cover classes identified in the study area.

Furthermore, the findings of this study as depicted in Figure 13, show that dense vegetation class had the highest percent coverage of 38.07, though with a decreasing trend, followed by sparse vegetation. Waterbody and barelands had the lowest area coverage. Also, the highest percent drop in its dense vegetated cover compared to other years. Sparse vegetation class witnessed a tremendous increase in its cover compared to 2014 with its area coverage exceeding 6000 ha.

\subsection{Analysis of LULC Classes for 2016 Image}

By 2016, all the LULC classes continue to experience dramatic changes in their area coverage (Figure 14 and Table 5). This change was twofold (positive and negative) with built-up, sparse vegetation and waterbody classes having a positive change. Dense vegetation and barelands classes showed a negative change in their area coverage.

The results further revealed that, despite the dramatic negative change in the dense vegetation cover it still maintained its high area of coverage with 16,629.85 ha, representing 51.08 percent of the total area of land use and covers (Table 5).

Table 6 shows the overall data onto the LULC changes trend from 2002 to 2016. Throughout the study period, there was a corresponding increase in the area coverage of the other land uses classes, particularly built-up area, sparse vegetation, as well as waterbodys.

\subsection{Change Trends of LULC Classes between 2002 and 2016}

The LULC classes by the year 2016 have assumed different dimensions of change

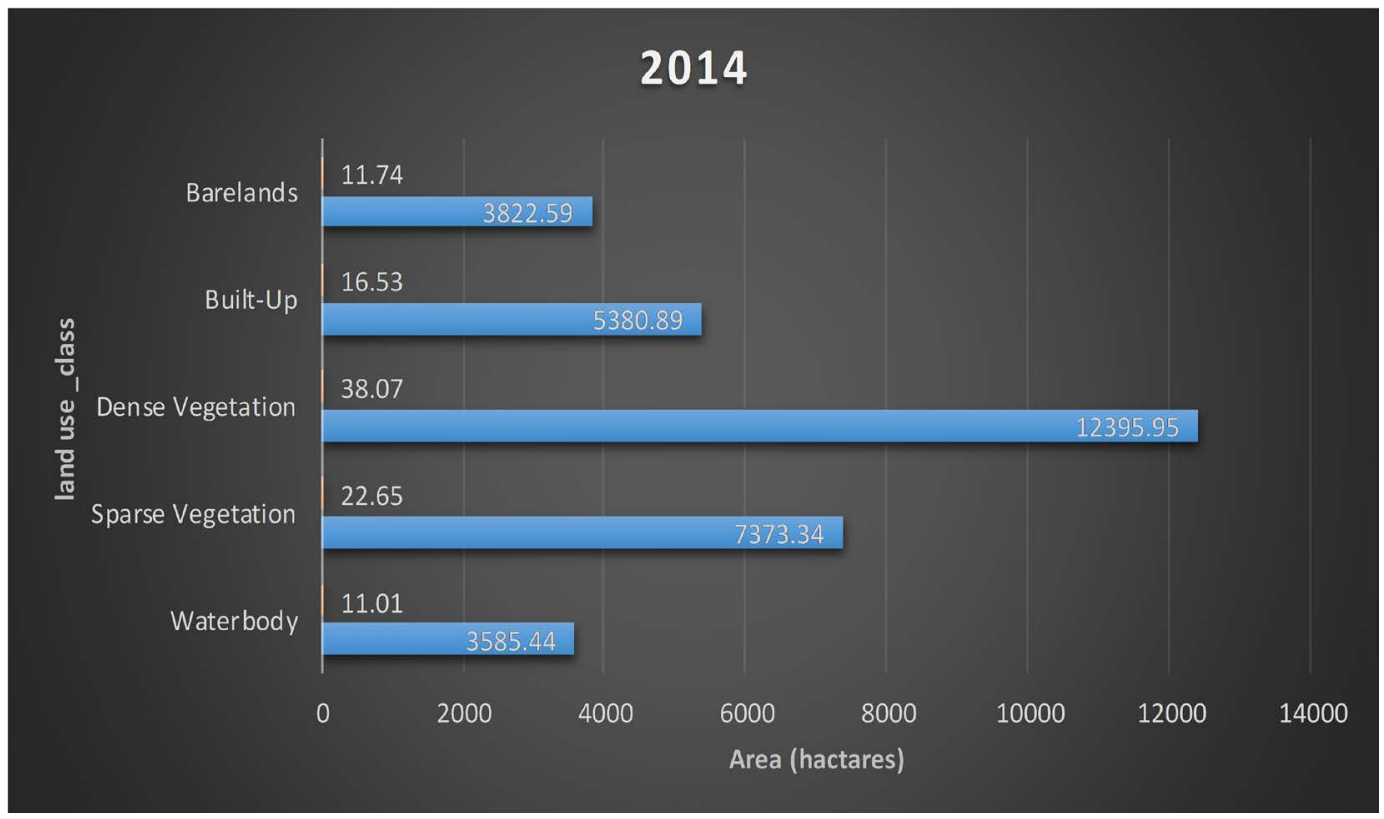

Figure 13. Land use land cover classes area (ha) for 2014. 


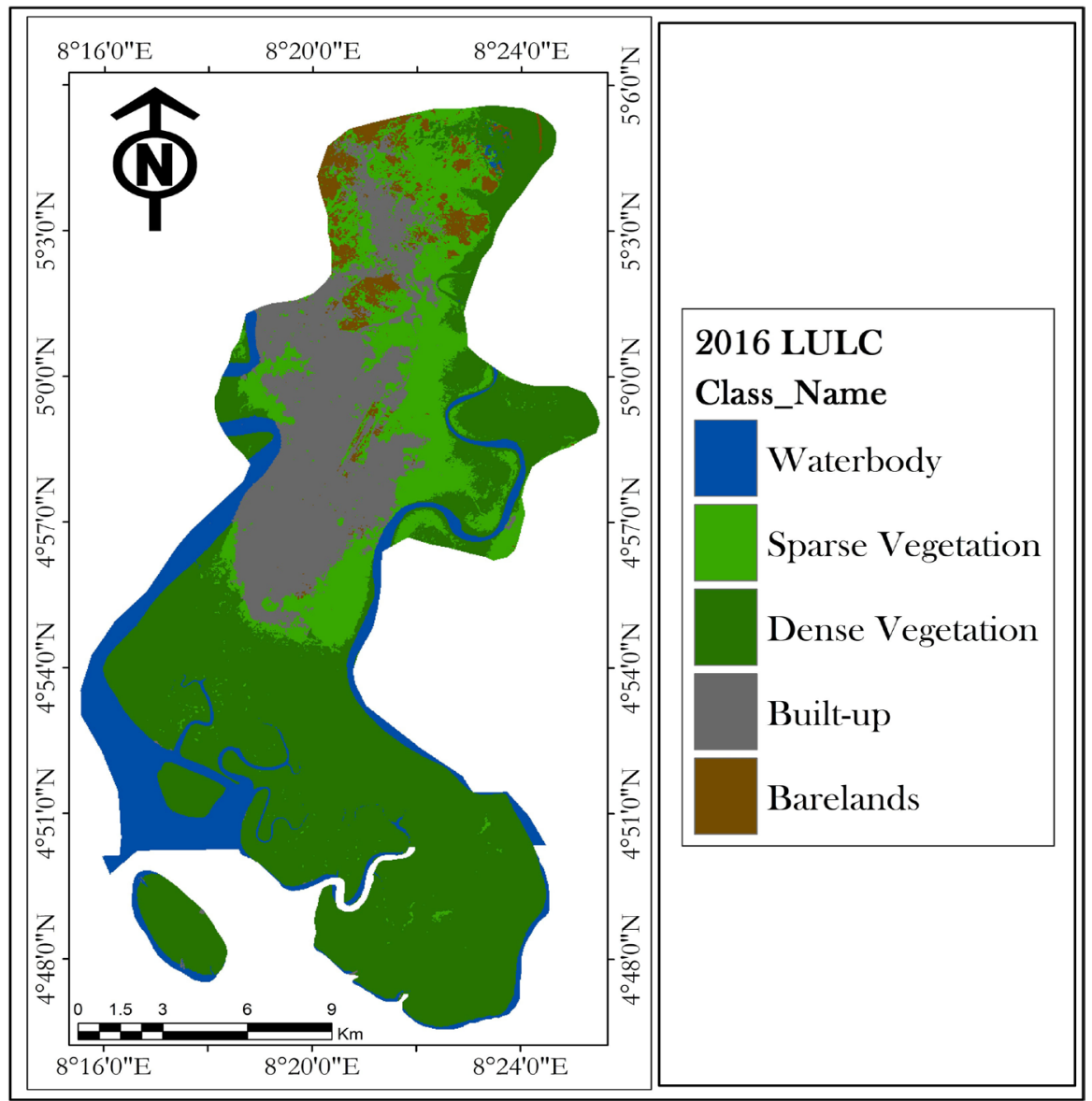

Figure 14. LULC Map of 2016 Landsat 8 OLI image.

Table 5. Area coverage (ha) of land cover types for 2016.

\begin{tabular}{ccc}
\hline Class Name & \multicolumn{2}{c}{2016} \\
\cline { 2 - 3 } & Area (ha) & $\%$ \\
\hline Waterbody & 3934.65 & 12.08 \\
Sparse Vegetation & 5262.53 & 16.16 \\
Dense Vegetation & 16629.85 & 51.08 \\
Built-Up & 5680.81 & 17.45 \\
Barelands & 1050.37 & 3.23 \\
& 32558.21 & \\
\hline
\end{tabular}

Table 6. Combined table of area data in hectares.

\begin{tabular}{|c|c|c|c|c|c|c|c|c|c|c|c|c|c|c|}
\hline \multirow{2}{*}{ Class Name } & \multicolumn{2}{|c|}{2002} & \multicolumn{2}{|c|}{2006} & \multicolumn{2}{|c|}{2008} & \multicolumn{2}{|c|}{2010} & \multicolumn{2}{|c|}{2012} & \multicolumn{2}{|c|}{2014} & \multicolumn{2}{|c|}{2016} \\
\hline & Area & $\%$ & Area & $\%$ & Area & $\%$ & Area & $\%$ & Area & $\%$ & Area & $\%$ & Area & $\%$ \\
\hline Waterbody & 3750.37 & 11.52 & 3544.67 & 10.89 & 3747.83 & 11.51 & 3468.49 & 10.65 & 3465.02 & 10.64 & 3585.44 & 11.01 & 3934.65 & 12.08 \\
\hline Sparse Vegetation & 3996.47 & 12.27 & 6744.36 & 20.71 & 5935.43 & 18.23 & 6413.92 & 19.70 & 4902.21 & 15.06 & 7373.34 & 22.65 & 5262.53 & 16.16 \\
\hline Dense Vegetation & 19861.42 & 61.00 & 16929.7 & 52.00 & 17897.57 & 54.97 & 16560.98 & 50.87 & 17760.39 & 54.55 & 12395.95 & 38.07 & 16629.85 & 51.08 \\
\hline Built-Up & 2865.19 & 8.80 & 3577.14 & 10.99 & 3942.37 & 12.11 & 4594.32 & 14.11 & 4776.88 & 14.67 & 5380.89 & 16.53 & 5680.81 & 17.45 \\
\hline \multirow[t]{2}{*}{ Barelands } & 2084.76 & 6.40 & 1762.34 & 5.41 & 1035.01 & 3.18 & 1520.5 & 4.67 & 1653.71 & 5.08 & 3822.59 & 11.74 & 1050.37 & 3.23 \\
\hline & 32558.21 & & 32558.21 & & 32558.21 & & 32558.21 & & 32558.21 & & 32558.21 & & 32558.21 & \\
\hline
\end{tabular}


in their sizes in comparison to their previous sizes (Table 7 and Figure 15) with some land uses having positive changes, others negative in the study period (2002 to 2016). The results further demonstrate that comparison between the two images (2002 and 2016) indicated an increase in the area coverage for built-up class, from 8.8 percent obtained in 2002 to 17.45 percent by 2016. Also, densely vegetated area has decreased from being 61 percent in 2002 to 51.08 percent of the total area in 2016 with a negative percentage change of -9.92 percent. On the other hand waterbody and barelands are the land use classes of the smallest area coverage in 2002, also had changes in their area coverage by 2016 with 0.56 percent and -3.17 percent changes in the waterbody and bare land classes respectively (Table 7 and Figure 15).

\section{Conclusion}

The findings of this study revealed that, the overall condition of the dense cover is decreasing from abundance and resilience. This is revealed by the decreasing NDVI values generated from the maps. The predominant negative trend in the LULC classes can also be attributed to the expansion, which can be explained by endogenous and exogenous factors such as, population growth through

Table 7. LULC percent cover and change from 2002 to 2016.

\begin{tabular}{cccc}
\hline Class Name & $\begin{array}{c}2002 \\
\%\end{array}$ & $\begin{array}{c}2016 \\
\%\end{array}$ & \% Change \\
\hline Waterbody & 11.52 & 12.08 & 0.56 \\
Sparse Vegetation & 12.27 & 16.16 & 3.89 \\
Dense Vegetation & 61 & 51.08 & -9.92 \\
Built-Up & 8.8 & 17.45 & 8.67 \\
Barelands & 6.4 & 3.23 & -3.17 \\
\hline
\end{tabular}

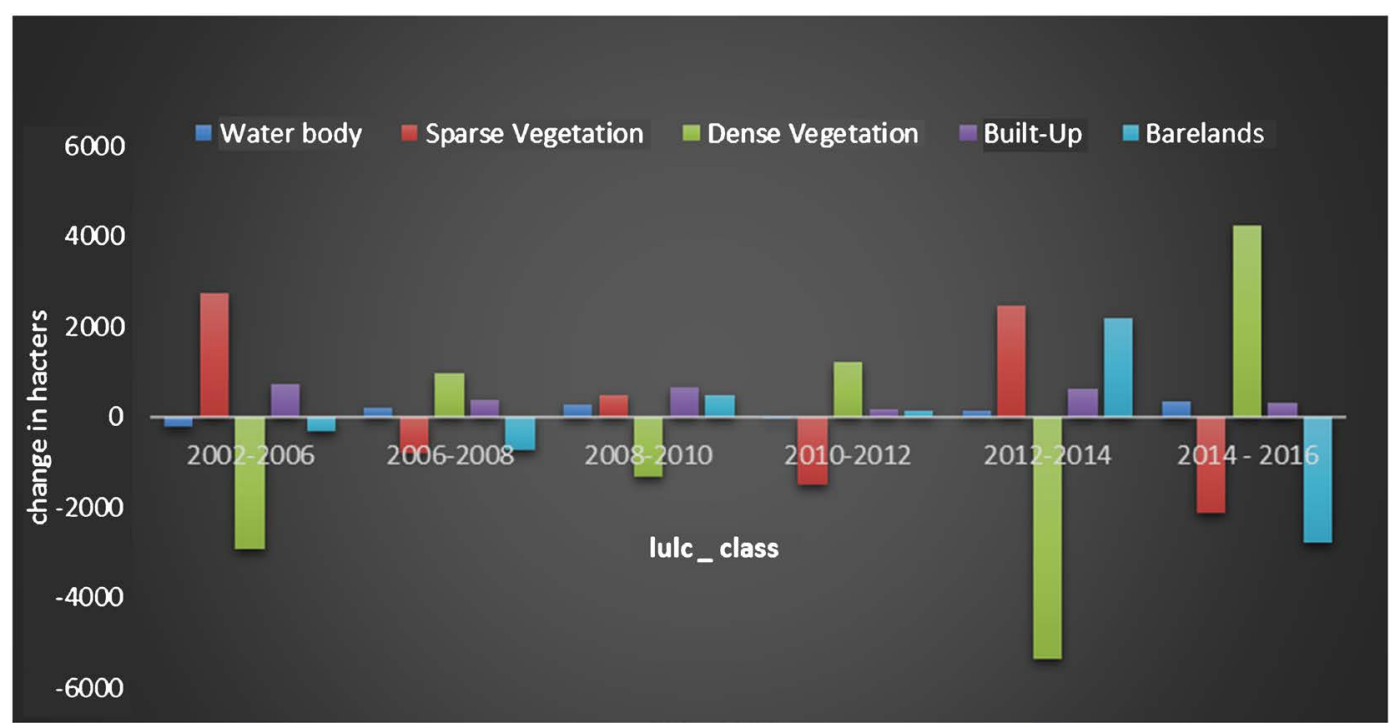

Figure 15. Change trends of LULC classes from 2002 to 2016. 
in-migration into the Calabar metropolis. Furthermore, the fact that vegetation, particularly dense covers is diminishing, using the evidence of the LULC classes, as revealed by the findings of this study which indicates that, future changing trends will pose a depleting threat to the overall LULC. The primary cause of these losses was the expansion of urban development. The increase in the built-up area can be attributed to the rapid urbanization of Calabar Metropolis. Transition from barelands to waterbody class can be attributed to sea level rises [15]. Lastly, though there is a moderate growth rate of built-up, bare land cover, efforts must be made to augment vegetation cover in Calabar Metropolis.

\section{Conflicts of Interest}

The authors declare no conflicts of interest regarding the publication of this paper.

\section{References}

[1] United Nations (2012) Global Land-Use Analysis.

[2] Awuh, M.E. (2017) Assessment of the Impact of Land-Use/Land Cover Pattern on Urban Heat Island in Calabar Metropolis. Unpublished Ph.D. Thesis, Nnamdi Azikiwe University, Awka.

[3] Wang, Y., Berardi, U. and Akbari, H. (2015) Comparing the Effects of Urban Heat Island Mitigation.

[4] Allegrini, J., Dorer, V. and Carmeliet, J. (2015) Influence of Morphologies on the Microclimate in Urban Neighbourhoods. Journal of Wind Engineering and Industrial Aerodynamics, 144, 108-117. https://doi.org/10.1016/j.jweia.2015.03.024

[5] Awuh, M.E. and Amawa, S.G. (2017) Urban Heat Island Coping/Adaptive. Strategies in Douala Metropolis Cameroon. Journal of Geography Meteorology and Environment Studies, 2, 50-57.

[6] Enete, I.C., Awuh, M.E. and Amawa, S. (2014) Assessment of Health Related Impacts of Urban Heat Island (UHI) in Douala Metropolis, Cameroon. International Journal of Environmental Protection and Policy, 2, 35-40.

[7] Brunsell, N.A. (2006) Characterization of Land-Surface Precipitation Feedback Regimes with Remote Sensing. Remote Sensing of Environment, 100, 200-211.

[8] Aslan, N. and Koc-San, D. (2016) Analysis of Relationship between UHI Effects \& Land Use/Cover Types Using Landsat $7 \mathrm{ETM}^{+}$and land sat 8 Oil Images. International Archives of the Photogrammetric, Remote Sensing and Spatial Information Sciences, XLI-B8, 821-828.

[9] Inyang, P.E.B. (1980) Calabar Environs: Geographical Studies. University of Calabar, Calabar.

[10] National Population Commission (NPC) [Nigeria] (2006) Population Census of the Federal Republic of Nigeria: Analytical Report at the National Level. Lagos.

[11] Eni, D.D. and Ukpong, B.J. (2014) The Impact of Population Growth on Residential Land Use in Calabar, Cross River State. Research on Humanities and Social Sciences, 4, 68-74.

[12] Alphan, H., Doygan, H. and Unlukapman, Y.I. (2008) Post Classification of Land Cover Using Multitemporal Landsat and ASTER Imagery: The Case of Kahramanmara, Turkey. Environmental Monitoring and Assessment, 51, 327-336. 
[13] Maingi, J.K. and Marsh S.E. (2002) An Accuracy Assessment of 1992 Landsat-MSS Derived Land Cover for the Upper San Pedro Watershed (US/Mexico). United States Environmental Protection Agency, Washington DC, 29 p.

[14] Congalton, R.G. (1988) Using Spatial Autocorrelation Analysis to Explore the Error in Maps Generated from Remotely Sensed Data. Photogrammetric Engineering \& Remote Sensing, 54, 587-592.

[15] Nigeria Meteorological Organization (NIMET) (2010) Climate Variability and Change: Impact, Science, Innovation and Policy. Climate Review Bulletin, 1-24. 